\title{
ARID3A Positivity Correlated With Favorable Prognosis in Patients With Residual Rectal Cancer After Neoadjuvant Chemoradiotherapy
}

\author{
GHILSUK YOON ${ }^{*}$, JEE YOUNG PARK ${ }^{1 *}$, HYE JIN KIM ${ }^{2}$, GYU SEOG CHOI ${ }^{2}$, \\ JONG GWANG KIM ${ }^{3}$, BYUNG WOOG KANG ${ }^{3}$, MIN KYU KANG ${ }^{4}$ and AN NA SEO ${ }^{1}$ \\ ${ }^{1}$ Department of Pathology, School of Medicine, Kyungpook National University, \\ Kyungpook National University Chilgok Hospital, Daegu, Republic of Korea; \\ ${ }^{2}$ Department of Surgery, School of Medicine, Kyungpook National University, \\ Kyungpook National University Chilgok Hospital, Daegu, Republic of Korea; \\ ${ }^{3}$ Department of Oncology/Hematology, School of Medicine, Kyungpook National University, \\ Kyungpook National University Chilgok Hospital, Daegu, Republic of Korea; \\ ${ }^{4}$ Department of Radiation Oncology, School of Medicine, Kyungpook National University, \\ Kyungpook National University Chilgok Hospital, Daegu, Republic of Korea
}

\begin{abstract}
Background/Aim: Recent studies have shown a marked increase of AT-rich interactive domain 3A (ARID3A) in colon cancer tissue compared to normal colon mucosa. However, the role of ARID3A has not yet been determined in rectal cancer. We, therefore, investigated the clinical relevance of ARID3A expression in patients with residual rectal cancer after neoadjuvant chemoradiotherapy (NACRT). Materials and Methods: One hundred thirty-four patients who underwent surgical resection for residual rectal cancer after NACRT were analyzed. ARID3A expression was evaluated using immunohistochemistry on whole-tissue sections. KRAS exon 2 (codons 12 and 13) and BRAF V600E mutation status were determined using polymerase chain reaction. Results: ARID3A positivity was found in 91 cases $(64.5 \%)$, and it correlated with absence of perineural invasion $(p=0.031)$, longer disease-free survival $(D F S)$ $(p=0.048)$ and cancer-specific survival (CSS) $(p=0.006)$. However, ARID3A positivity was not correlated with KRAS $(p=0.231)$ or BRAF mutation status $(p=0.577)$. In
\end{abstract}

\footnotetext{
*These Authors contributed equally to this work.

Correspondence to: An Na Seo, MD, Ph.D., Department of Pathology, School of Medicine, Kyungpook National University, Kyungpook National University Chilgok Hospital, 807 Hogukno, Buk-gu, Daegu, Republic of Korea. Tel: +82 532003403, Fax: +82 532003399, e-mail: san_0729@naver.com

Key Words: Rectal cancer, neoadjuvant chemoradiotherapy, AT-rich interactive domain $3 \mathrm{~A}$, prognostic marker.
}

multivariate analysis, ARID3A positivity was independently associated with a favorable CSS ( $p=0.035)$, but not DFS $(p=0.051)$. Conclusion: ARID3A positivity can predict favorable prognosis in patients with residual rectal cancer after NACRT.

Despite early diagnosis, advancement in surgical techniques, and improved adjuvant chemotherapeutic regimens, colorectal cancer (CRC) remains one of the major leading causes of cancer-related deaths worldwide (1). An increasing body of evidence indicates that rectal cancer is a distinct form of colon cancer with different aetiology, risk factors, and genetic and epigenetic alterations (2). The incidence of rectal cancer is approximately $35 \%$ of the total CRC incidence (2). Neoadjuvant chemoradiotherapy (NACRT) followed by total mesorectal excision (TME) is the standard treatment for locally advanced stage II/III rectal cancer (3, 4). The pathological complete response (pCR) of NACRT is associated with low rates of local and distant recurrence (2, $5)$. However, to the best of our knowledge, there are no known surrogate markers that can predict patient response to radiotherapy (RT) or chemoradiotherapy (CRT) (2). Furthermore, in clinical practice, the majority of patients with rectal cancer treated with NACRT fail to achieve a pCR $(2,5)$. In this context, identification of novel prognostic genes and/or downstream pathways controlling the tumor growth is pivotal for the development of treatment strategies for patients with residual rectal cancer treated with NACRT.

In 2012, Kang et al. identified the AT-rich interactive domain 3A (ARID3A) in the protein expression profiling of microsatellite-stable (MSS) CRC using proteomic techniques 
(6). Of the differentially expressed proteins in normal and cancer tissues, ARID3A expression level was approximately 14.29-fold higher in cancer tissues than in paired normal tissues. In 2017, Liu et al. found that ARID3A was upregulated in CRC, by performing integrated analysis of microarray studies and verified it using The Cancer Genome Atlas (TCGA) data sets and quantitative real-time polymerase chain reaction (qRT-PCR) (7). ARID3A encodes a member of the ARID family of DNA-binding proteins known as B-cell regulator of immunoglobulin heavy-chain transcription (BRIGHT)/DRIL1/E2FBP1 (8-11), and it is homologous to the Drosophila dead ringer gene, which is important for normal embryogenesis (11). ARID3A is expressed ubiquitously in various tissues, playing a role in various biological processes (8-11). However, to date, the clinical relevance of ARID3A in human disease has not been fully elucidated. In particular, very few studies have reported the role of ARID3A in CRC. Recently, Song et al. demonstrated that ARID3A overexpression was an independent prognostic factor for favorable overall survival (OS) in 690 patients with CRC (8). Interestingly, they also performed survival analysis according to tumor location (colon versus rectum), separately, and showed that ARID3A overexpression was significantly correlated with favorable OS in patients with colon cancer but not in patients with rectal cancer (8). However, in their study, patients with rectal cancer were preoperative chemo- or radiotherapy-naïve. Thus, whether ARID3A overexpression is associated with the outcomes of patients with locally advanced mid or low rectal cancer treated with NACRT ought to be examined.

In the present study, we aimed to evaluate the clinical significance and prognostic impact of ARID3A expression in residual rectal disease after NACRT in patients with surgically resected rectal cancer by pathological assessment and immunohistochemistry.

\section{Patients and Methods}

Patient selection. A retrospective series of patients described in previous our studies were analyzed in the present study (12-14). Between January 2006 and December 2011, 134 patients with residual rectal cancer after NACRT who underwent surgical resection at Kyungpook National University Hospital and Chilgok Hospital (Daegu, South Korea) and were diagnosed with mid or low rectal adenocarcinoma were included in the study. Patients showing distant metastasis at initial diagnosis, and patients who achieved pCR were excluded from the study. Clinical information data of patients were obtained by reviewing their medical records and pathologic reports. In addition, one experienced gastrointestinal pathologist (ANS) reviewed the haematoxylin and eosin-stained slides and re-confirmed the pathologic assessment. Tumors were categorised according to the 7th UICC/AJCC TNM cancer classification system (15).

Ethical statement. This study was approved by the Institutional Review Board of Kyungpook National University Medical Center
(IRB No: 2014-04-215), and the requirement for obtaining informed consent from patients was waived. This study was carried out according to the 1964 Declaration of Helsinki and its later amendments or comparable ethical standards.

Pre-treatment and surgery. All patients with clinical T3, T4, or node-positive disease were treated with NACRT in accordance with our institutional practice strategy and had regular follow-up (16). In long-course radiotherapy, a total radiation dose of 45 or $50 \mathrm{~Gy}$ is delivered in 25 fractions ( 1.8 or 2 Gy per fraction, respectively) five times per week for 5 weeks. The chemotherapy regimen involved the administration of 5-fluorouracil (5-FU), either as a bolus infusion $\left(425 \mathrm{mg} / \mathrm{m}^{2} /\right.$ day $)$ plus leucovorin $\left(20 \mathrm{mg} / \mathrm{m}^{2} /\right.$ day $)$ or as a continuous infusion, 5 days a week $\left(250 \mathrm{mg} / \mathrm{m}^{2} /\right.$ day $)$ during radiotherapy. Curative surgical resection was performed within 6-8 weeks after the completion of NACRT. TME with autonomic nerve preservation was performed following the standard surgical procedure, which comprised of low anterior, intersphincteric, and abdominoperineal resection. All patients received treatment according to the standard practice guidelines and were followed regularly after surgery.

Pathological assessment. All specimens were fixed in $10 \%$ neutralbuffered formalin fluid overnight after inking the periphery of the mesorectum and cutting into transverse sections. For obvious residual primary tumor, initially, at least 6 tissue blocks were obtained from the tumor area. If the tumor was absent or not visible, the whole tumor area was blocked. If the tumor was still absent, each tumor block was thoroughly sectioned. CRM-positivity was defined as a tumor infiltration of $\leq 1 \mathrm{~mm}$ from the dyed fascia recti (17). The pathological tumor response to NACRT was assessed according to a previous report by Rödel et al. $(5,18)$ : grade $0=$ no regression, grade $1=$ minor regression, grade $2=$ moderate regression, grade $3=$ good regression and grade $4=$ total regression (ypCR). If absence of tumor cells in tumors with acellular mucin pools in the whole tissue was demonstrated by immunohistochemistry (IHC) for cytokeratin, tumors were considered as ypCR and excluded from the study.

This work has been reported in line with the Reporting Recommendations for Tumor Marker Prognostic Studies (REMARK) criteria (19).

IHC and interpretation. IHC was performed on $4 \mu \mathrm{m}$ wholesections of formalin-fixed paraffin-embedded (FFPE) tissues using Ventana Bench Mark ${ }^{\circledR}$ XT Autostainer (Ventana Medical Systems, Tucson, AZ, USA) with the ultraView Universal DAB Kit (Ventana Medical Systems) and antibodies against ARID3A (1:100; ProteinTech Group, Chicago, IL, USA) and p53 (1:800; Dako, Glostrup, Denmark), according to the manufacturer's instructions. Briefly, all tissue sections were deparaffinized and rehydrated, and antigens were retrieved for $40 \mathrm{~min}$ in a citrate buffer $(\mathrm{pH} 6.1)$ at $95^{\circ} \mathrm{C}$. DAB was used as the chromogen, and the sections were counterstained with haematoxylin.

Two experienced pathologists (ANS and JYP), blinded to the patient clinical information, evaluated ARID3A and p53 expression. Both ARID3A and p53 proteins were expressed in the nuclei of tumor cells. Because there is no consensus for ARID3A staining interpretation in rectal cancer, the quantitation was performed according to the previous report (8). When no ARID3A expression or weak/faint expression was observed in tumor cells, the specimen 
was regarded as negative. In contrast, tumor specimens that showed $\geq 50 \%$ immunostaining with moderately/strongly intensity at low power magnification (40-100 $\times$ objective) were considered as positive. Expression of p53 was measured as the percentage of cells showing definite nuclear staining and scored using a semiquantitative grading. Tumor samples with $\geq 10 \%$ positive nuclear staining were considered positive, as described previously (20).

KRAS and BRAF mutation detection. KRAS exon 2 (codons 12 and 13) and BRAF V600E mutation status was confirmed by PNAmediated real-time polymerase chain reaction using the PNAClamp $^{\mathrm{TM}} K R A S$ and PNAClamp ${ }^{\mathrm{TM}}$ BRAF Mutation Detection Kit (Panagene, Daejeon, Korea) according to the manufacturer's procedure (21). KRAS and BRAF mutation status has already been analyzed previously $(12,13)$.

Statistical analyses. Statistical analyses were carried out using IBM SPSS version 19.0 (IBM Co., Armonk, NY, USA). The association between ARID3A and p53 expression and clinicopathological data was determined using the $\chi^{2}$ or Fisher's exact test for categorical variables, as appropriate. Pearson correlation $(\mathrm{R})$ test was used to evaluate the correlation between ARID3A and p53 expression. Two survival end points were evaluated: (1) disease-free survival (DFS), defined as the time interval between surgery and the date of disease relapse or death, and (2) cancer-specific survival (CSS), defined as the time interval between surgery and death caused by the disease. The Kaplan-Meier method was used to estimate DFS and CSS curves, and the log-rank test was used to compare between groups. A multivariate Cox regression analysis was performed, including all variables that were significantly associated with prognosis in the univariate analysis. Hazard ratios (HRs) and their 95\% confidence intervals (CIs) were estimated for each factor. Statistical significance was considered as $p<0.05$.

\section{Results}

Patient characteristics. The demographic characteristics of the study cohort are summarised in Table I. The patient group included 93 males $(69.4 \%)$ and 41 females (30.6\%), with a median age of 60 years (range $=29-85$ ). At the time of surgical resection after NACRT, 27 (20.1\%) tumors were ystage I, $64(47.8 \%)$ were ystage II, and $43(32.1 \%)$ were ystage III, according to the 7th UICC/AJCC. Among 100 patients with $K R A S$ and $B R A F$ mutation results available, 29 patients $(29.0 \%)$ harboured a KRAS mutation, whereas 4 $(4.0 \%)$ harboured a $B R A F$ mutation.

Correlations between ARID3A and clinicopathological data. Figure 1 shows representative images of tumor specimens with positive expression of ARID3A and p53. ARID3A expression was evaluated in all the cases $(n=134)$, whereas p53 expression was not evaluable in 4 of the 134 cases, because of the loss of tissues. ARID3A positivity was found in 91 of $134(67.9 \%)$ patients, whereas p53 positivity was observed in 99 of $130(76.2 \%)$ patients. No statistically significant correlation between ARID3A positivity and $\mathrm{p} 53$ positivity was found $(\mathrm{R}=0.077, p=0.386)$. As shown in Table
Table I. Patient characteristics.

\begin{tabular}{|c|c|}
\hline Characteristics & $\mathrm{n}(\%)$ \\
\hline Age at diagnosis, years* & $60.0(29-85)$ \\
\hline \multicolumn{2}{|l|}{ Gender } \\
\hline Male & $93(69.4)$ \\
\hline Female & $41(30.6)$ \\
\hline \multicolumn{2}{|c|}{ Tumor distance from anal verge } \\
\hline$<5$ & $102(76.1)$ \\
\hline$\geq 5$ & $32(23.9)$ \\
\hline Tumor size* & $6.0(2.3-10.0)$ \\
\hline \multicolumn{2}{|l|}{ Clinical $\mathrm{T}$ category } \\
\hline $\mathrm{cT} 2$ & $8(6.0)$ \\
\hline $\mathrm{cT} 3$ & $109(81.3)$ \\
\hline cT4 & $17(12.7)$ \\
\hline \multicolumn{2}{|l|}{ Clinical N category } \\
\hline $\mathrm{cNO}$ & $15(11.2)$ \\
\hline $\mathrm{cN} 1-3$ & $119(88.8)$ \\
\hline \multicolumn{2}{|l|}{ Pathologic $\mathrm{T}$ category } \\
\hline ypT1 & $2(1.5)$ \\
\hline урТ2 & $31(23.1)$ \\
\hline урT3 & $92(68.7)$ \\
\hline ypT4 & $9(6.7)$ \\
\hline \multicolumn{2}{|l|}{ Pathologic N category } \\
\hline ypN0 & $91(67.9)$ \\
\hline ypN1-3 & $43(32.1)$ \\
\hline \multicolumn{2}{|c|}{ Pathologic TNM stage (7th UICC/AJCC) } \\
\hline I & $27(20.1)$ \\
\hline II & $64(47.8)$ \\
\hline III & $43(32.1)$ \\
\hline \multicolumn{2}{|l|}{ CRM status } \\
\hline Negative & $105(78.4)$ \\
\hline Positive & $29(21.6)$ \\
\hline \multicolumn{2}{|l|}{ Preoperative CEA ${ }^{\mathrm{a}}$} \\
\hline$<5$ & $86(68.8)$ \\
\hline$\geq 5$ & $39(31.2)$ \\
\hline \multicolumn{2}{|l|}{ Tumor regression grade ${ }^{b}$} \\
\hline 0 & $4(3.0)$ \\
\hline 1 & $21(15.7)$ \\
\hline 2 & $54(40.3)$ \\
\hline 3 & $55(41.0)$ \\
\hline \multicolumn{2}{|c|}{ Downstage after neoadjuvant chemoradiotherapy } \\
\hline No & 49 (36.6) \\
\hline Yes & $85(63.4)$ \\
\hline \multicolumn{2}{|l|}{ KRAS mutation ${ }^{\mathrm{c}}$} \\
\hline Wild & $71(71.0)$ \\
\hline Mutant & $29(29.0)$ \\
\hline \multicolumn{2}{|l|}{$B R A F$ mutation ${ }^{\mathrm{c}}$} \\
\hline Wild & $96(96.0)$ \\
\hline Mutant & $4(4.0)$ \\
\hline
\end{tabular}

TNM, Tumor-node-metastasis; UICC/AJCC, Union for International Cancer Control/American Joint Committee on Cancer; CRM, circumferential resection margin; CEA, carcinoembryonic antigen. *Data presented as median (range). aPatients who had pathologic complete remission (tumor regression grade 4 ) were excluded in this study. ${ }^{b}$ Missing value was included. ${ }^{c} K R A S$ and $B R A F$ mutations were assessed in 100 patients. 

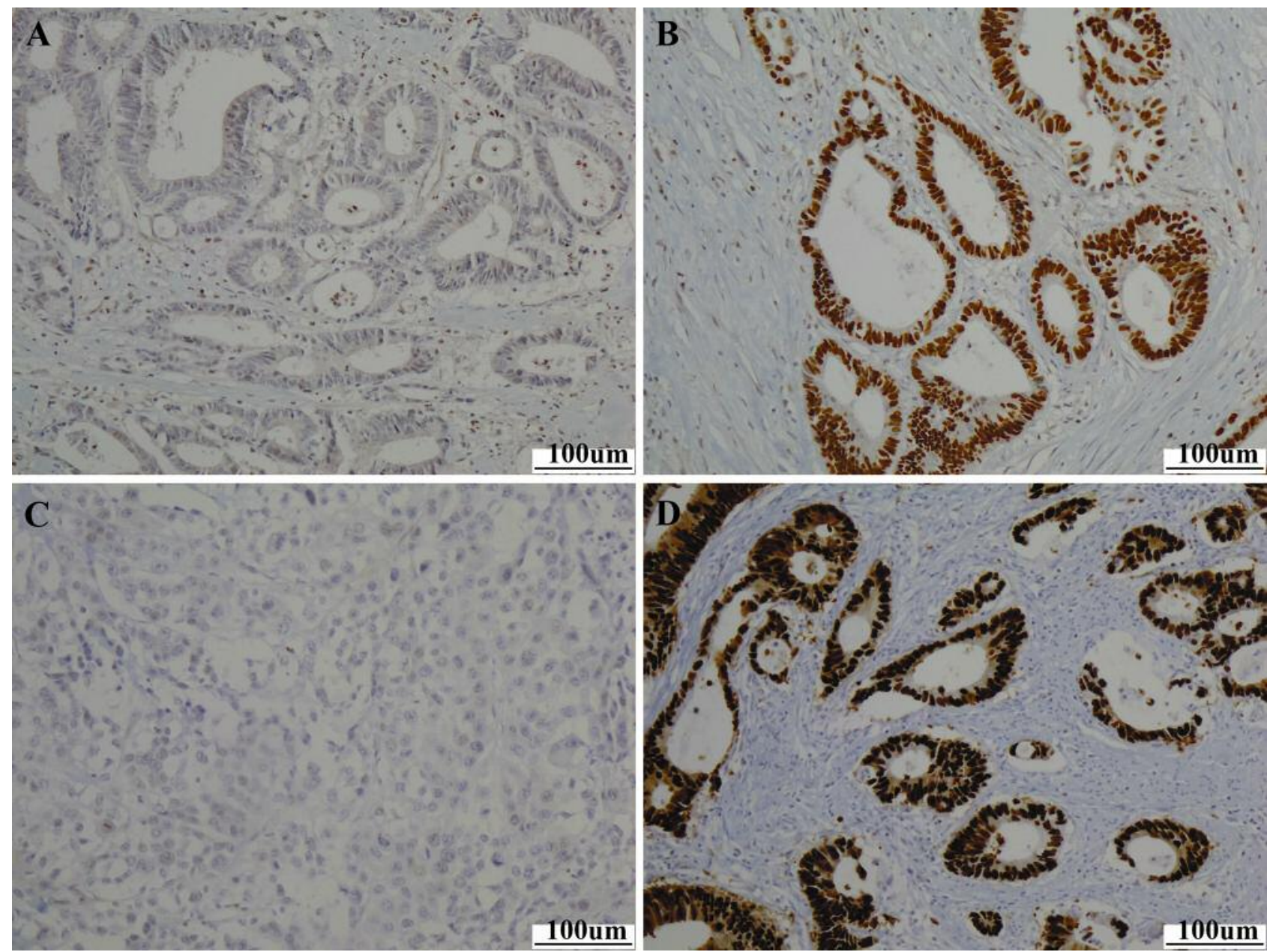

Figure 1. The expression of ARID3A and p53 proteins in rectal cancer specimens was assessed by immunohistochemistry. Representative images of negative (A) and positive (B) staining for ARID3A, as well as negative (C) and positive for $p 53(D)$ are shown. 200x magnification; Scale bar 100 um.

II, ARID3A positivity inversely correlated with perineural invasion $(p=0.031)$, whereas $\mathrm{p} 53$ positivity had no association with any clinicopathological parameters. Neither ARID3A nor p53 positivity was related to KRAS or BRAF mutations (Table II).

Survival outcomes. At the time of analysis, the median follow-up durations for DFS and CSS were 47.7 (range $=2.2$ 111.0) and 48.3 (range=3.2-111.0) months, respectively. During follow-up period, 53 (39.6\%) experienced recurrence and $22(16.4 \%)$ died of rectal cancer. Patients with ARID3A positivity showed a significantly longer DFS ( $p=0.048$; Figure 2A) and CSS ( $p=0.006$; Figure $2 \mathrm{~B}$ ) than those with ARID3A negativity. In contrast, p53 positivity was not significantly associated with DFS ( $p=0.493$; Figure 2 C) or CSS ( $p=0.354$; Figure 2D). In a Cox proportional hazard model adjusted for ypT category, ypN category, lymphatic invasion, perineural invasion, venous invasion, and CRM status, ARID3A positivity was an independent prognostic factor for favorable CSS (HR=2.655, 95\% CI=1.072-6.576, $p=0.035$; Table III). There was no statistical significance between DFS and ARID3A expression ( $\mathrm{HR}=1.778,95 \%$ $\mathrm{CI}=0.998-3.166, p=0.051$; Table III).

\section{Discussion}

In patients with rectal cancer, after NACRT, the goals of care include decreasing the risk of recurrence and optimizing the length of life. As previously mentioned, a pCR after NACRT is associated with low rates of local recurrence and distant metastasis. However, because the majority of patients with residual disease do not achieve $\mathrm{pCR}$, the use of surrogate markers that can predict patient outcomes is necessary. Herein, we evaluated whether ARID3A expression could 
Table II. The association between clinicopathologic parameters and AT-rich interactive domain 3A (ARID3A) and p53 protein expressions.

\begin{tabular}{|c|c|c|c|c|c|c|}
\hline \multirow[t]{2}{*}{$\begin{array}{l}\text { Clinicopathologic } \\
\text { characteristics }\end{array}$} & \multicolumn{2}{|c|}{$\begin{array}{l}\text { ARID3A expression } \\
\qquad(\mathrm{n}=134)\end{array}$} & \multirow[t]{2}{*}{$p$-Value } & \multicolumn{2}{|c|}{$\begin{array}{l}\text { p53 expression }{ }^{\mathrm{a}} \\
(\mathrm{n}=130)\end{array}$} & \multirow[t]{2}{*}{$p$-Value } \\
\hline & $\begin{array}{l}\text { Negative } \\
\mathrm{n}(\%)\end{array}$ & $\begin{array}{c}\text { Positive } \\
\text { n (\%) }\end{array}$ & & $\begin{array}{l}\text { Negative } \\
\mathrm{n}(\%)\end{array}$ & $\begin{array}{l}\text { Positive } \\
\text { n (\%) }\end{array}$ & \\
\hline \multicolumn{7}{|c|}{ Age at diagnosis, years } \\
\hline$<60$ & $17(39.5)$ & $47(51.6)$ & \multirow[t]{2}{*}{0.201} & $14(45.2)$ & $46(46.5)$ & \multirow[t]{2}{*}{1.000} \\
\hline$\geq 60$ & $26(60.5)$ & $44(48.4)$ & & $17(54.8)$ & $53(53.5)$ & \\
\hline \multicolumn{7}{|l|}{ Gender } \\
\hline Male & $26(60.5)$ & $67(73.6)$ & \multirow[t]{2}{*}{0.160} & $24(77.4)$ & $66(66.7)$ & \multirow[t]{2}{*}{0.277} \\
\hline Female & $17(39.5)$ & $24(26.4)$ & & $7(22.6)$ & $33(33.3)$ & \\
\hline \multicolumn{7}{|c|}{ Tumor distance from anal verge, $\mathrm{cm}$} \\
\hline$<5$ & $33(76.7)$ & $69(75.8)$ & \multirow[t]{2}{*}{1.000} & $21(67.7)$ & $78(78.8)$ & \multirow[t]{2}{*}{0.231} \\
\hline$\geq 5$ & $10(23.3)$ & $22(24.2)$ & & $10(32.3)$ & $21(21.2)$ & \\
\hline \multicolumn{7}{|c|}{ Preoperative CEA, ng/mb } \\
\hline$<5$ & $28(70.0)$ & $58(68.2)$ & \multirow[t]{2}{*}{1.000} & $19(67.9)$ & $64(68.8)$ & \multirow[t]{2}{*}{1.000} \\
\hline$\geq 5$ & $12(30.0)$ & $27(31.8)$ & & $9(32.1)$ & $29(31.2)$ & \\
\hline \multicolumn{7}{|l|}{ Tumor size, $\mathrm{cm}$} \\
\hline$<6$ & $23(53.5)$ & $44(48.4)$ & \multirow[t]{2}{*}{0.712} & $17(54.8)$ & $47(47.5)$ & \multirow[t]{2}{*}{0.540} \\
\hline$\geq 6$ & $20(46.5)$ & $47(51.6)$ & & $14(45.2)$ & $52(52.5)$ & \\
\hline Pathologic $\mathrm{T}$ categ & & & & & & \\
\hline урT1-T2 & $11(25.6)$ & $22(24.2)$ & 1.000 & $1(3.2)$ & $7(7.1)$ & 0.679 \\
\hline урT3-T4 & $32(74.4)$ & $69(75.8)$ & & $30(96.8)$ & $92(92.9)$ & \\
\hline Pathologic $\mathrm{N}$ catę & & & & & & \\
\hline ypNo & $25(58.1)$ & $66(72.5)$ & 0.114 & $2(6.5)$ & $13(13.1)$ & 0.520 \\
\hline ypN1-3 & $18(41.9)$ & $25(27.5)$ & & $29(93.5)$ & $86(86.9)$ & \\
\hline Pathologic TNM s & & & & & & \\
\hline I \& II & $25(58.1)$ & $66(72.5)$ & 0.114 & $23(74.2)$ & $66(66.7)$ & 0.511 \\
\hline III & $18(41.9)$ & $25(27.5)$ & & $8(25.8)$ & $33(33.3)$ & \\
\hline Downstage after $n$ & & & & & & \\
\hline No & $20(46.5)$ & $29(31.9)$ & 0.125 & $9(29.0)$ & $38(38.4)$ & 0.397 \\
\hline Yes & $23(53.5)$ & $62(68.1)$ & & $22(71.0)$ & $61(61.6)$ & \\
\hline CRM status & & & & & & \\
\hline Negative & $35(81.4)$ & $70(76.9)$ & 0.656 & $27(87.1)$ & $76(76.8)$ & 0.311 \\
\hline Positive & $8(18.6)$ & $21(23.1)$ & & $4(12.9)$ & $23(23.2)$ & \\
\hline Tumor regression & & & & & & \\
\hline 0 & $2(4.7)$ & $2(2.2)$ & 0.181 & $2(6.5)$ & $2(2.0)$ & 0.592 \\
\hline 1 & $8(18.6)$ & $13(14.3)$ & & $5(16.1)$ & $16(16.2)$ & \\
\hline 2 & $12(27.9)$ & $42(46.2)$ & & $11(35.5)$ & $41(41.4)$ & \\
\hline 3 & $21(48.8)$ & $34(37.4)$ & & 13 (41.9) & $40(40.4)$ & \\
\hline Lymphatic invasio & & & & & & \\
\hline Negative & $29(67.4)$ & $73(80.2)$ & 0.130 & $24(77.4)$ & $75(75.8)$ & 1.000 \\
\hline Positive & $14(32.6)$ & $18(19.8)$ & & 7 (22.6) & $24(24.2)$ & \\
\hline Venous invasion & & & & & & \\
\hline Negative & $40(93.0)$ & $89(97.8)$ & 0.327 & $29(93.5)$ & $96(97.0)$ & 0.592 \\
\hline Positive & $3(7.0)$ & $2(2.2)$ & & $2(6.5)$ & $3(3.0)$ & \\
\hline Perineural invasio & & & & & & \\
\hline Negative & $27(62.8)$ & $74(81.3)$ & 0.031 & $22(71.0)$ & 77 (77.8) & 0.473 \\
\hline Positive & $16(37.2)$ & 17 (18.7) & & $9(29.0)$ & $22(22.2)$ & \\
\hline$K R A S$ mutation $^{\mathrm{d}}$ & & & & & & \\
\hline Wild & $18(62.1)$ & $53(74.6)$ & 0.231 & $20(80.0)$ & $49(68.1)$ & 0.313 \\
\hline Mutant & $11(37.9)$ & $18(25.4)$ & & $5(20.0)$ & $23(31.9)$ & \\
\hline$B R A F$ mutation $^{\mathrm{d}}$ & & & & & & \\
\hline Wild & $27(93.1)$ & $69(97.2)$ & 0.577 & $24(96.0)$ & $69(95.8)$ & 1.000 \\
\hline Mutant & $2(6.9)$ & $2(2.8)$ & & $1(4.0)$ & $3(4.2)$ & \\
\hline
\end{tabular}

TNM, Tumor-node-metastasis; UICC/AJCC, Union for International Cancer Control/American Joint Committee on Cancer; CRM, circumferential resection margin; CEA, carcinoembryonic antigen. ${ }^{\text {ap}} 53$ protein expression was evaluated in 130 patients. ${ }^{b}$ Missing value was included. ${ }^{\mathrm{c} P a t i e n t s}$ who had pathological complete remission (tumor regression grade 4) were excluded in this study. ${ }^{\mathrm{d}} K R A S$ and $B R A F$ mutations were assessed in 100 patients. 


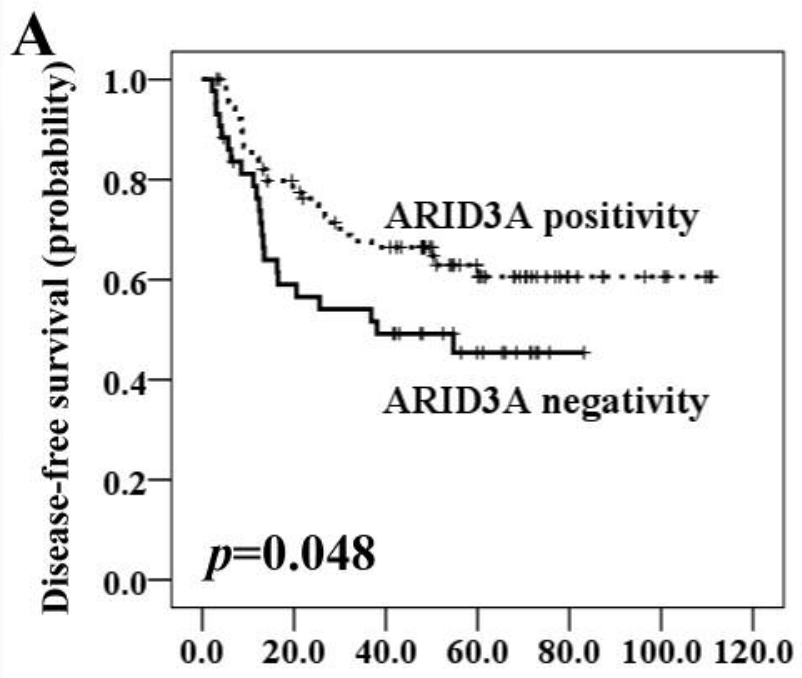

Time (months)

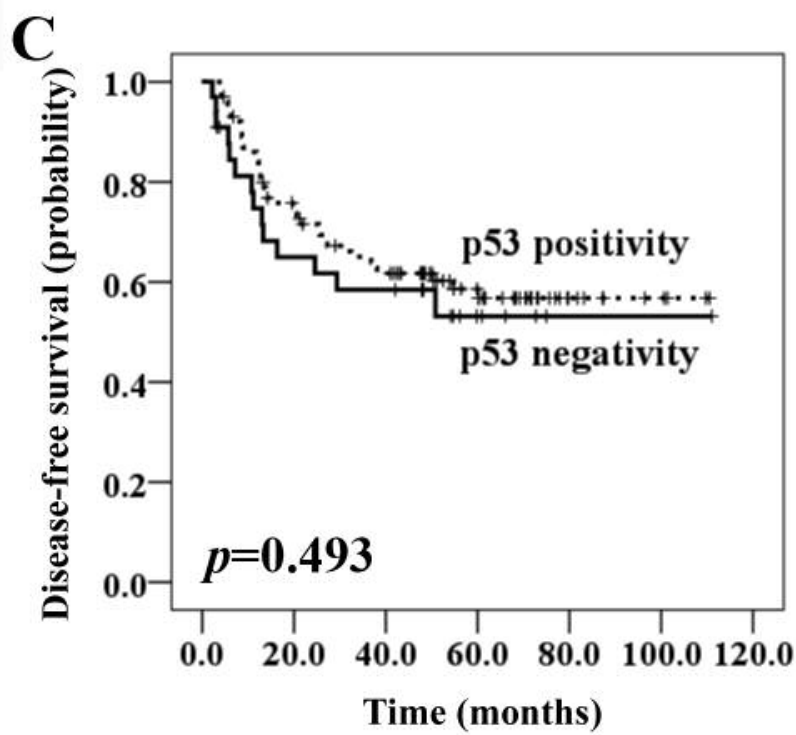

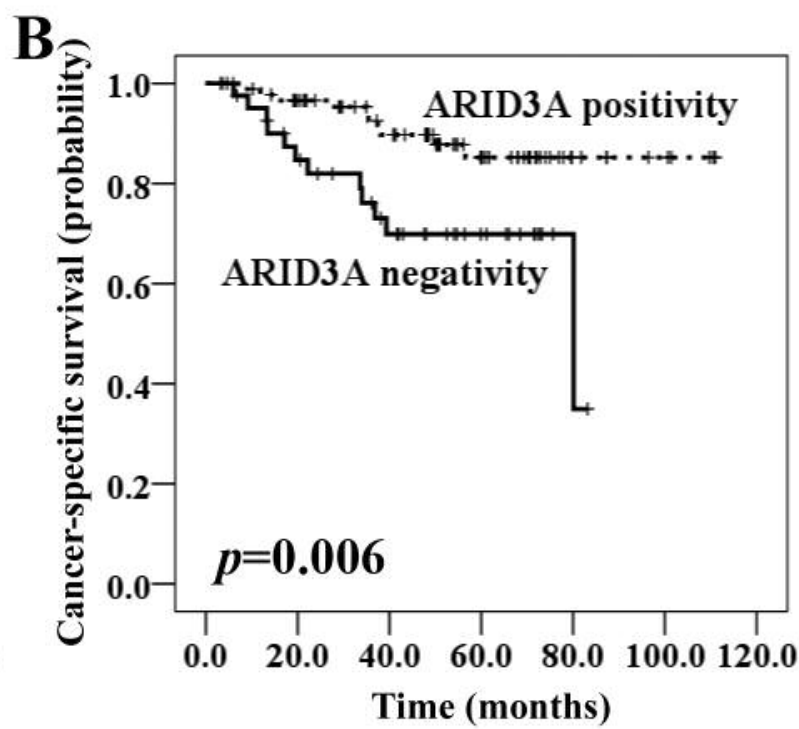

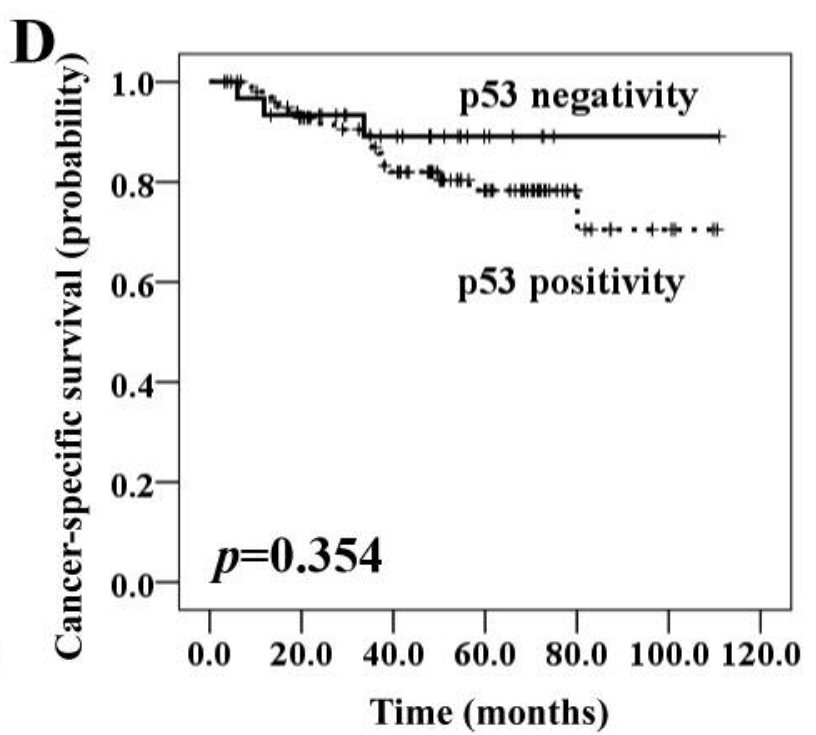

Figure 2. Kaplan-Meier survival curves for disease-free survival (DFS) (A) and cancer-specific survival (CSS) (B) according to the expression of ARID3A. Kaplan-Meier survival curves for DFS (C) and CSS (D) according to the expression of p53.

predict prognosis of patients who developed residual rectal cancer after NACRT. The rationale was supported by the study by Song et al., which showed that strong nuclear expression of ARID3A can independently predict favorable OS in patients with CRC (8). We also found that strong nuclear expression of ARID3A was significantly associated with improved CSS in patients with residual rectal cancer after NACRT, independent of the standard prognostic and predictive factors (ypT category, ypN category, lymphatic invasion, venous invasion, perineural invasion, and CRM). To the best of our knowledge, there have been no studies investigating the prognostic significance of ARID3A in rectal cancer after NACRT. Interestingly, we found ARID3A positivity in $69.4 \%$ of residual rectal cancer after NACRT, whereas Song et al. observed in $30 \%$ of rectal cancer with preoperative chemotherapy or radiotherapy naïve (8). This difference of frequency might be due to tumor location (midor low- rectum versus upper rectum) and/or NACRT.

Although ARID3A/BRIGHT expression in adults was originally thought to be limited to cells of the $B$ lymphocyte lineage, studies have revealed that ARID3A is expressed in multiple foetal, embryonic, and placental 
Table III. Multivariate analyses for disease-free survival (DFS) and cancer-specific survival (CSS).

\begin{tabular}{|c|c|c|c|c|c|c|c|}
\hline \multirow{3}{*}{ Variable } & \multirow{3}{*}{ Category } & \multicolumn{3}{|c|}{ DFS } & \multicolumn{3}{|c|}{ CSS } \\
\hline & & \multicolumn{3}{|c|}{ Multivariate analysis } & \multicolumn{3}{|c|}{ Multivariate analysis } \\
\hline & & HR & $95 \% \mathrm{CI}$ & $p$-Value & HR & $95 \% \mathrm{CI}$ & $p$-Value \\
\hline ypT category & урТ1-Т2 vs. урТ3-Т4 & 2.567 & $0.962-6.849$ & 0.060 & 95104.564 & $0.000-1.06 \mathrm{E} 172$ & 0.953 \\
\hline $\mathrm{ypN}$ category & ypN0 vs. ypN1-3 & 1.788 & $0.878-3.639$ & 0.109 & 3.991 & $1.255-12.692$ & 0.019 \\
\hline Venous invasion & Absent $v s$. Present & 17.577 & 4.759-64.918 & $<0.001$ & 2.631 & $0.666-10.393$ & 0.168 \\
\hline Lymphatic invasion & Absent vs. Present & 1.272 & $0.638-2.535$ & 0.495 & 1.971 & $0.702-5.533$ & 0.197 \\
\hline Perineural invasion & Absent vs. Present & 1.362 & $0.724-2.563$ & 0.338 & 3.493 & $1.278-9.544$ & 0.015 \\
\hline CRM & Negative $v s$. Positive & 3.391 & $1.840-6.250$ & $<0.001$ & 6.849 & $2.540-18.465$ & $<0.001$ \\
\hline ARID3A expression & Negative $v s$. Positive & 1.778 & $0.998-3.166$ & 0.051 & 2.655 & $1.072-6.576$ & 0.035 \\
\hline
\end{tabular}

HR, Hazard ratio; CI, confidence interval; CRM, circumferential resection margin; ARID3A, AT-rich interactive domain 3A.

tissues, as well as in adult hematopoietic stem cells (22-27). Of note, abnormal ARID3A expression is associated with increased proliferative capacity and malignancy; however, ARID3A may play distinct regulatory roles in different types of cells (25). In CRC, Liu et al. demonstrated that REGEL, CA1, ANGPTL7, TMEFF2, and ZNF354C were downregulated, whereas ARID3A was upregulated among the differentially expressed genes (DEGs) and their transcription factors (TFs) in CRC. In the light of previous studies, ARID3A might be a potential oncogenic factor (6, 7). ARID3A is an upstream TF of ESM1 and could be involved in CRC by regulating ESM1 (7). However, high ARID3A expression was associated with favorable prognosis in the present study as well as in the study published by Song et al. (8). Thus, the mechanisms that regulate ARID3A expression in tumor cells remain unknown. ARID3A is known to repress the formation of promyelocytic leukaemia (PML) nuclear bodies (28). PML can actively promote Ras-induced senescence and modify the tumor-suppressor effects of the retinoblastoma protein (Rb) and p53 pathways (29). Oncogenic Ras can upregulate PML expression, which, in turn, induces senescence in a p53-dependent manner (30). Contrastingly, other studies have reported the function of ARID3A as a tumor suppressor (9, 31). Ma et al. suggested that ARID3A expression can be activated by p53 and, in parallel, can increase endogenous p53 levels in a dose-dependent manner after DNA damage $(9,10)$. They also showed that ARID3A could inhibit tumor cell growth in cells with wild-type p53, but not in cells lacking p53 (9). Lestari et al. demonstrated that ARID3A plays important roles in p53-mediated p21Waf1 transactivation and that modulation of ARID3A levels affects $\mathrm{p} 53$ protein stability, providing interdependent and cooperative roles for ARID3A and p53 proteins in transcriptional activation of $\mathrm{p} 21 \mathrm{Waf} 1$ in response to DNA damage (31). This means that ARID3A may play a key role in p53-mediated tumor growth suppression $(8,9)$. However, in the present study, we found no significant association between ARID3A and p53 protein expression. In addition, we did not found any correlation between p53 expression and TRG as well as prognosis. Terzi et al. suggested that IHC assessment of p53 in pre-treatment biopsy specimens does not predict TRG and prognosis (32). In contrast, Chen et al. demonstrated that wild-type form of p53 status was associated with good response rates to neoadjuvant radiation-based treatment by performing meta-analysis of 30 studies (33).

Thus far, whether ARID3A acts as an oncogene or as a tumor suppressor remains controversial. This is because of the distinct roles influenced by ARID3A during the cell cycle in different cell types that result from different interactions with different cooperating factors or maturation states (25). Therefore, further comprehensive studies taking into account these findings are necessary.

One limitation of our study is selection bias due to the retrospective design from a single institution, the relatively small number of patients with residual rectal cancer after NACRT, and the lack of comparison of ARID3A expression between pre-treatment biopsy and post-treatment surgical tissues. Hence, our findings should be interpreted with caution, and further large-scale studies should be carried out to validate these results in other ethnic groups.

In summary, we demonstrated that ARID3A overexpression is an independent prognostic factor for CSS in patients with surgically resected residual rectal cancer after NACRT. Although the underlying mechanism requires further research, our results indicate that ARID3A plays an important role in rectal cancer. These findings would be helpful in uncovering the biological mechanism and develop novel therapeutic targets in patients with residual rectal cancer after NACRT. 


\section{Conflicts of Interest}

The Authors declare no conflicts of interest.

\section{Authors' Contributions}

A.N. Seo had substantial contributions to the conception or design of the work. G. Yoon and A.N. Seo wrote the first draft and the revised draft, and then reviewed the final article. J.Y. Park and A.N. Seo performed the experiments. A.N. Seo performed the statistical analyses. H.J. Kim, G.S. Choi, J.G. Kim, B.W. Kang, and M.K. Kang collected and interpreted the clinical data and specimens. All authors approved the final version and agreed to be accountable for all aspects of the work.

\section{Acknowledgements}

This work was supported by Biomedical Research Institute grant, Kyungpook National University Hospital (2016).

\section{References}

1 Oh CM, Won YJ, Jung KW, Kong HJ, Cho H, Lee JK, Lee DH and Lee KH: Cancer statistics in Korea: Incidence, mortality, survival, and prevalence in 2013. Cancer Res Treat 48(2): 436450, 2016. PMID: 28279062. DOI: 10.4143/crt.2017.118

2 Glynne-Jones R, Wyrwicz L, Tiret E, Brown G, Rodel C, Cervantes A and Arnold D: Rectal cancer: Esmo clinical practice guidelines for diagnosis, treatment and follow-up. Ann Oncol 28(suppl_4): iv22-iv40, 2017. PMID: 28881920. DOI: 10.1093/ annonc/mdx224

3 Sauer R, Becker H, Hohenberger W, Rodel C, Wittekind C, Fietkau R, Martus P, Tschmelitsch J, Hager E, Hess CF, Karstens JH, Liersch T, Schmidberger H and Raab R: Preoperative versus postoperative chemoradiotherapy for rectal cancer. N Engl J Med 351(17): 1731-1740, 2004. PMID: 15496622. DOI: 10.1056/NEJMoa040694

4 Sauer R, Liersch T, Merkel S, Fietkau R, Hohenberger W, Hess C, Becker H, Raab HR, Villanueva MT, Witzigmann H, Wittekind C, Beissbarth T and Rodel C: Preoperative versus postoperative chemoradiotherapy for locally advanced rectal cancer: Results of the german cao/aro/aio-94 randomized phase iii trial after a median follow-up of 11 years. J Clin Oncol 30(16): 1926-1933, 2012. PMID: 22529255. DOI: 10.1200/ JCO.2011.40.1836

5 Rodel C, Martus P, Papadoupolos T, Fuzesi L, Klimpfinger M, Fietkau R, Liersch T, Hohenberger W, Raab R, Sauer R and Wittekind C: Prognostic significance of tumor regression after preoperative chemoradiotherapy for rectal cancer. J Clin Oncol 23(34): 8688-8696, 2005. PMID: 16246976. DOI: 10.1200/ JCO.2005.02.1329

6 Kang UB, Yeom J, Kim HJ, Kim H and Lee C: Expression profiling of more than 3500 proteins of mss-type colorectal cancer by stable isotope labeling and mass spectrometry. J Proteomics 75(10): 3050-3062, 2012. PMID: 22154799. DOI: 10.1016/j.jprot.2011.11.021

7 Liu HY and Zhang CJ: Identification of differentially expressed genes and their upstream regulators in colorectal cancer. Cancer Gene Therapy 24(6): 244-250, 2017. PMID: 28409560. DOI: $10.1038 / \mathrm{cgt} .2017 .8$
8 Song M, Kim H, Kim WK, Hong SP, Lee C and Kim H: High expression of at-rich interactive domain $3 \mathrm{a}$ (arid3a) is associated with good prognosis in colorectal carcinoma. Ann Surg Oncol 21(Suppl 4): S481-489, 2014. PMID: 24366420. DOI: 10.1245/s10434-013-3435-2

9 Ma K, Araki K, Ichwan SJ, Suganuma T, Tamamori-Adachi M and Ikeda MA: E2fbp1/dril1, an at-rich interaction domainfamily transcription factor, is regulated by p53. Mol Cancer Res 1(6): 438-444, 2003. PMID: 12692263.

$10 \mathrm{Ma} \mathrm{K}$ : [Involvement of e2fbp1, an arid family member protein, in the p53 regulatory pathway]. Kokubyo Gakkai Zasshi 69(2): 152-161, 2002. PMID: 12136662.

11 Kortschak RD, Reimann H, Zimmer M, Eyre HJ, Saint R and Jenne DE: The human dead ringer/bright homolog, drill: Cdna cloning, gene structure, and mapping to d19s886, a marker on 19 p13.3 that is strictly linked to the peutz-jeghers syndrome. Genomics 51(2): 288-292, 1998. PMID: 9722953. DOI: 10.1006/geno.1998.5259

12 Yoon G, Kim SM, Kim HJ and Seo AN: Clinical influence of cancer stem cells on residual disease after preoperative chemoradiotherapy for rectal cancer. Tumour Biol 37(3): 35713580, 2016. PMID: 26456957. DOI: 10.1007/s13277-015-4201-9

13 Yoon G, Lee H, Kim JH, Hur K and Seo AN: Clinical significance of fibroblast growth factor receptor 2 expression in patients with residual rectal cancer after preoperative chemoradiotherapy: Relationship with kras or braf mutations and msi status. Tumour Biol 37(8): 10209-10218, 2016. PMID: 26831663. DOI: $10.1007 / \mathrm{s} 13277-016-4899-\mathrm{z}$

14 Park JS, Yoon G, Kim HJ, Park SY, Choi GS, Kang MK, Kim JG, Jang JS and Seo AN: Her2 status in patients with residual rectal cancer after preoperative chemoradiotherapy: The relationship with molecular results and clinicopathologic features. Virchows Arch 473(4): 413-423, 2018. PMID: 30056472. DOI: 10.1007/s00428-018-2409-y

15 Edge SB, Byrd DR, Compton C, Fritz A, Greene F and Trotti A (eds.): AJCC Cancer Staging Handbook: From the AJCC Cancer Staging Manual. New York, Springer, 2010.

16 Kim HJ, Choi GS, Park JS, Park S, Kawai K and Watanabe T: Clinical significance of thrombocytosis before preoperative chemoradiotherapy in rectal cancer: Predicting pathologic tumor response and oncologic outcome. Ann Surg Oncol 22(2): 513519, 2015. PMID: 25145505. DOI: 10.1245/s10434-014-3988-8

17 Rullier A, Gourgou-Bourgade S, Jarlier M, Bibeau F, ChassagneClement C, Hennequin C, Tisseau L, Leroux A, Ettore F, Peoc'h M, Diebold MA, Robin YM, Kleinclaus I, Mineur L, Petitjean C, Mosnier JF, Soubeyran I, Padilla N, Lemaistre AI, Berille J, Denis B, Conroy T and Gerard JP: Predictive factors of positive circumferential resection margin after radiochemotherapy for rectal cancer: The french randomised trial accord12/0405 prodige 2. Eur J Cancer 49(1): 82-89, 2013. PMID: 22909998. DOI: $10.1016 /$ j.ejca.2012.06.028

18 Dworak O, Keilholz L and Hoffmann A: Pathological features of rectal cancer after preoperative radiochemotherapy. Int J Colorectal Dis 12(1): 19-23, 1997. PMID: 9112145.

19 McShane LM, Altman DG, Sauerbrei W, Taube SE, Gion M and Clark GM: Reporting recommendations for tumor marker prognostic studies. J Clin Oncol 23(36): 9067-9072, 2005. PMID: 16172462. DOI: 10.1200/JCO.2004.01.0454

20 Allegra CJ, Paik S, Colangelo LH, Parr AL, Kirsch I, Kim G, Klein P, Johnston PG, Wolmark N and Wieand HS: Prognostic 
value of thymidylate synthase, ki-67, and p53 in patients with dukes' $b$ and c colon cancer: A national cancer institute-national surgical adjuvant breast and bowel project collaborative study. J Clin Oncol 21(2): 241-250, 2003. PMID: 12525515. DOI: 10.1200/JCO.2003.05.044

21 Kwon MJ, Lee SE, Kang SY and Choi YL: Frequency of kras, braf, and pik3ca mutations in advanced colorectal cancers: Comparison of peptide nucleic acid-mediated PCR clamping and direct sequencing in formalin-fixed, paraffin-embedded tissue. Pathol Res Pract 207(12): 762-768, 2011. PMID: 22070922 DOI: $10.1016 /$ j.prp.2011.10.002

22 Webb CF: The transcription factor, bright, and immunoglobulin heavy chain expression. Immunol Res 24(2): 149-161, 2001. PMID: 11594453. DOI: 10.1385/IR:24:2:149

23 Ratliff ML, Mishra M, Frank MB, Guthridge JM and Webb CF: The transcription factor arid3a is important for in vitro differentiation of human hematopoietic progenitors. J Immunol 196(2): 614-623, 2016. PMID: 26685208. DOI: 10.4049/ jimmunol.1500355

24 Ratliff ML, Ward JM, Merrill JT, James JA and Webb CF: Differential expression of the transcription factor arid3a in lupus patient hematopoietic progenitor cells. J Immunol 194(3): 940949, 2015. PMID: 25535283. DOI: 10.4049/jimmunol.1401941

25 Ratliff ML, Templeton TD, Ward JM and Webb CF: The bright side of hematopoiesis: Regulatory roles of arid3a/bright in human and mouse hematopoiesis. Front Immunol 5: 113, 2014. PMID: 24678314. DOI: 10.3389/fimmu.2014.00113

26 Rhee C, Lee BK, Beck S, Anjum A, Cook KR, Popowski M, Tucker HO and Kim J: Arid3a is essential to execution of the first cell fate decision via direct embryonic and extraembryonic transcriptional regulation. Genes Dev 28(20): 2219-2232, 2014. PMID: 25319825. DOI: 10.1101/gad.247163.114

27 Rhee C, Edwards M, Dang C, Harris J, Brown M, Kim J and Tucker HO: Arid3a is required for mammalian placenta development. Dev Biol 422(2): 83-91, 2017. PMID: 27965054. DOI: $10.1016 /$ j.ydbio.2016.12.003
28 Fukuyo Y, Mogi K, Tsunematsu Y and Nakajima T: E2fbp1/hdril1 modulates cell growth through downregulation of promyelocytic leukemia bodies. Cell Death Differ 11(7): 747-759, 2004. PMID: 15017387. DOI: $10.1038 /$ sj.cdd.4401412

29 Ferbeyre G, de Stanchina E, Querido E, Baptiste N, Prives C and Lowe SW: Pml is induced by oncogenic ras and promotes premature senescence. Genes Dev 14(16): 2015-2027, 2000. PMID: 10950866.

30 Pearson M, Carbone R, Sebastiani C, Cioce M, Fagioli M, Saito S, Higashimoto Y, Appella E, Minucci S, Pandolfi PP and Pelicci PG: PML regulates p53 acetylation and premature senescence induced by oncogenic Ras. Nature 406(6792): 207-210, 2000. PMID: 10910364. DOI: 10.1038/35018127

31 Lestari W, Ichwan SJ, Otsu M, Yamada S, Iseki S, Shimizu S and Ikeda MA: Cooperation between Arid3a and p53 in the transcriptional activation of $\mathrm{p} 21 \mathrm{waf} 1$ in response to DNA damage. Biochem Biophys Res Commun 417(2): 710-716, 2012. PMID: 22172947. DOI: 10.1016/j.bbrc.2011.12.003

32 Terzi C, Canda AE, Sagol O, Atila K, Sonmez D, Fuzun M, Gorken IB, Oztop I and Obuz F: Survivin, p53, and ki-67 as predictors of histopathologic response in locally advanced rectal cancer treated with preoperative chemoradiotherapy. Int J Colorectal Dis 23(1): 37-45, 2008. PMID: 17805549. DOI: 10.1007/s00384-007-0376-x

33 Chen MB, Wu XY, Yu R, Li C, Wang LQ, Shen W and Lu PH: P53 status as a predictive biomarker for patients receiving neoadjuvant radiation-based treatment: A meta-analysis in rectal cancer. PLoS One 7(9): e45388, 2012. PMID: 23049793. DOI: 10.1371/journal.pone.0045388
Received April 1, 2019

Revised May 18, 2019

Accepted May 20, 2019 